\title{
Student Research
}

\section{A longitudinal study to determine association of various maternal factors with neonatal birth weight at a tertiary care hospital}

\author{
Lt Akshay Misra ${ }^{a}$, Surg Capt Sougat Ray ${ }^{b, *}$, Seema Patrikar ${ }^{c}$ \\ a Intern, Military Hospital, Jalandhar, India \\ ${ }^{\mathrm{b}}$ Commanding Officer, INHS Navjivani, Kerala, India \\ ${ }^{\mathrm{c}}$ Lecturer in Biostatistics \& Demography, Dept of Community Medicine, Armed Forces Medical College, Pune 411040, \\ India
}

\section{A R T I C L E I N F O}

Article history:

Received 9 January 2014

Accepted 10 March 2015

Available online 5 May 2015

\section{Keywords:}

Maternal diet

BMI

Gestational weight gain

Birth weight

Food frequency questionnaire

\begin{abstract}
A B S T R A C T
Background: Neonatal birth weight is a powerful predictor of infant growth and survival and maternal factors like poor knowledge and insufficient dietary intake are significant risk factors. Other preventable determinants like pre pregnant BMI $<18.5$, low gestational weight gain (GWG) and anemia are also associated with low birth weight. This study was carried out to identify the impact of these maternal factors with risk of low birth weight (LBW).

Methods: A longitudinal study was carried out on 124 booked antenatal cases at a tertiary care center. A validated protocol containing socio demography, food frequency and anthropometry was administered at the 3rd trimester. Birth weight of the newborn was noted after delivery.

Results: $26.28 \%$ children had low birth weight $(<2500 \mathrm{~g}), 14.6 \%$ mothers were thin (BMI < 18.5), 55.3\% mothers had a weight gain of less than $9 \mathrm{kgs}$ and $45.5 \%$ were anemic. $81.81 \%$ mothers with BMI $>18.5$ and $28.92 \%$ women who were educated till high school had a baby with LBW. Most mothers consumed milk and vegetables daily and a few consumed non vegetarian foods but quality and quantity of food were grossly inadequate. GWG levels and $\mathrm{Hb}$ levels were significantly different in different birth weight groups and also were significantly associated with low birth weight.

Conclusion: Quality and quantity of maternal dietary intake during pregnancy, even in normal weight mothers (BMI > 18.5), are important determinants of birth weight. Nutritional counseling for mothers during the antenatal period is the cornerstone for healthy mother and healthy child.
\end{abstract}

(c) 2015, Armed Forces Medical Services (AFMS). All rights reserved.

\footnotetext{
* Corresponding author. Tel.: +91 8390367279.

E-mail address: sougatray@hotmail.com (S. Ray). http://dx.doi.org/10.1016/j.mjafi.2015.03.001

0377-1237/@ 2015, Armed Forces Medical Services (AFMS). All rights reserved.
} 


\section{Introduction}

More than 20 million infants worldwide are born with low birth weight (<2500 gm). Birth weight is a significant factor which determines vulnerability for risk of childhood infections and survival. Studies have highlighted strong associations between LBW and poor academic performance and problems related to mental, behavioral and learning difficulties later in life. At the population level, maternal factors like poor knowledge and nutritional deficiency not only predicts the present intrauterine development, but is also associated with low birth weight. ${ }^{1,2}$ Maternal undernutrition still remain pervasive in low and middle income countries with damaging consequences. Independent factors like pre pregnancy body mass index (BMI), gestational weight gain (GWG) and anemia in pregnancy, are direct markers of intrauterine growth and birth weight.

The prevalence of maternal undernutrition with respect to BMI $<18.5 \mathrm{~kg} / \mathrm{m}^{2}$ ranges from $10 \%$ to $19 \%$ in most countries. This is a serious problem in sub-Saharan Africa and southeastern Asia, where more than $20 \%$ of women have a BMI $<18.5 \mathrm{~kg} / \mathrm{m}^{2}$ but the situation is critical in India ${ }^{3}$ where the prevalence of low BMI is $40 \%$ in women. One of the most important modifiers of weight gain in pregnancy and its impact on the health of the mother and the baby is the woman's weight at the start of the pregnancy. The range of weight gain as per the Institute of Medicine ${ }^{4}$ recommendations are more $(12-18 \mathrm{~kg})$ for those with a pre pregnant BMI $<18.5$ than for those who are obese (11-13 kg). Indian standards however, suggest a normal weight gain of $09-14 \mathrm{kgs}^{5}$ during pregnancy.

An extra amount of $350 \mathrm{Kcal}$ of energy and $30 \mathrm{~g} \mathrm{protein}^{5}$ is required during pregnancy but in most of the cases, there is hardly any difference in intake of protein and energy between the pre pregnant and pregnant states in Indian women. The consumption of foods that are important sources of protein and energy, such as dairy products, meat, fish, green leafy vegetables and soyabean is also low in rural Indian populations.

This longitudinal study was carried out to identify the impact of maternal factors like knowledge, BMI, GWG, anemia and dietary habits with risk of low birth weight in a tertiary care hospital.

\section{Materials and methods}

The assessment of maternal nutrition requires the measurement of body mass index (during initial pregnancy), weight gain during pregnancy, determination of measurement of patterns of food intake, and biochemical measurements of micronutrient status. All cases were subjected to height and weight measurements at 32-34 weeks by standard equipment (SECA) and BMI was calculated. BMI and Hemoglobin levels of the 1st trimester were derived from the antenatal cards. GWG was calculated from the difference in weight gain. Birth weight was taken during the first hour of birth to the nearest $50 \mathrm{~g}$ using a Salter spring balance. A validated pilot tested protocol containing socio demography, semi quantitative food frequency questionnaire and history of past illness was administered.
Taking the prevalence of low birth weight to be $20 \%$ as per NFHS $3^{2}$ and with a desired precision of $7 \%$, the sample size was calculated to be 123 . All booked cases were included by systematic random sampling. Known cases of diabetes, hypertension, twin pregnancy, congenital malformation or any other chronic diseases were excluded. Due consent was taken and the study was cleared by the institutional ethical committee. The data collected was analyzed using SPSS Ver 20.

\section{Results}

This study was conducted at a tertiary care centre and in mothers without any complication. Most of the mothers were from an urban slum. We found $26.28 \%$ children to be having low birth weight, $14.6 \%$ mothers to be thin (BMI < 18.5), $55.3 \%$ mothers to be having a weight gain of less than $9 \mathrm{kgs}$ and $45.5 \%$ were anemic. Of the thin mothers, 06 of them had a low birth weight baby, whereas in the normal or overweight mothers, 27 of them had a similar outcome. 28.92\% women who were educated till high school had a baby with LBW. There was a positive association (not significant) between the selected sociodemographic parameters and antenatal care parameters with birth weight (Table 1).

From the semi quantitative food frequency questionnaire, it was observed that $64.2 \%$ women consumed non vegetarian foods with chicken being the most common meat but mean intake of such food was only $100 \mathrm{~g}$ twice a week. 57 out of 79 (72.16\%) non vegetarians had normal birth weight outcome. One glass of milk was consumed by $76 \%$ daily, but most $(51.2 \%)$ of them consumed milk only once a week. Again $26.38 \%$ of the women who consumed milk had a low weight baby. Most of mothers (39.8\%) used soyabean oil but average use was $25 \mathrm{ml}$ per day.

The mean birth weight was $2.79 \mathrm{kgs}$ and mean GWG was $9.73 \mathrm{~kg}$. GWG levels and Hb levels were significantly different in different birth weight groups and also were significantly associated with low birth weight (Table 2). The mean BMI was however not significantly different (ANOVA).

\section{Discussion}

We studied the birth weight of urban Indian newborn babies in relation to their mothers' knowledge and their nutritional status in pregnancy.

The study found a higher prevalence of neonatal low birth weight than that of the national data (NFHS 3). We found $14.6 \%$ mothers to be thin (BMI of $<18.5$ ). More than half of the mothers had a less than recommended weight gain and almost half of them were anemic. Most studies and surveys conducted in India and elsewhere have found maternal literacy, undernourishment ${ }^{3}$ and anemia ${ }^{3}$ to have profound effects on maternal weight gain and birth weight and same have been corroborated in this study. In our study, infants born to $36 \%$ mothers with GWG $<9$ kgs were at increased risk for fetal growth deficits, which is similar to a study from north India. ${ }^{6}$ $45.5 \%$ women were anemic ( $\mathrm{Hb}<10.9 \mathrm{gm} \%)$ similar to other studies $^{3,7,8}$ and were more likely to have a low birth weight baby. However, 27 mothers with normal BMI (>18.5) had a low 
Table 1 - Distribution of sociodemographic factors and antenatal care factors with birth weight in the study population.

\begin{tabular}{|c|c|c|c|c|c|}
\hline & \multirow[t]{2}{*}{ Frequency } & \multicolumn{2}{|c|}{ Birth weight } & \multirow[t]{2}{*}{ OR (95\% CI) } & \multirow[t]{2}{*}{ Chi Square (p) } \\
\hline & & $<2.5 \mathrm{~kg}$ & $>2.5 \mathrm{~kg}$ & & \\
\hline \multicolumn{6}{|c|}{ Selected sociodemographic factors } \\
\hline \multicolumn{6}{|l|}{ Mother's literacy } \\
\hline Till high school level & $83(67.47)(100)$ & $24(72.73)(28.92)$ & $59(65.56)(71.08)$ & $1.40(0.58-3.09)$ & 0.41 \\
\hline Grad and post grad & $40(32.53)(100)$ & $9(27.27)(22.50)$ & $31(34.34)(77.50)$ & & \\
\hline \multicolumn{6}{|l|}{ Para } \\
\hline Multipara & $78(63.41)$ & $22(66.7)$ & $56(62.2)$ & $1.21(0.52-2.81)$ & 0.67 \\
\hline Primipara & $45(36.59)$ & $11(33.3)$ & $34(37.8)$ & & \\
\hline \multicolumn{6}{|l|}{ Diet } \\
\hline Non vegetarian & $79(64.22)$ & $23(69.7)$ & $56(62.2)$ & $1.39(0.59-3.2)$ & 0.44 \\
\hline Vegetarian & $44(35.77)$ & $10(30.3)$ & $34(37.8)$ & & \\
\hline \multicolumn{6}{|c|}{ Antenatal care parameters } \\
\hline \multicolumn{6}{|l|}{ BMI } \\
\hline $\mathrm{BMI}<18.4$ & 18 (14.6) & $6(18.2)$ & $12(13.5)$ & 1.43 (CI 0.43-4.64) & 0.53 \\
\hline BMI $18.5-24.9$ & $86(69.9)$ & $24(72.7)$ & $62(69.7)$ & & \\
\hline BMI $>25$ & 19 (14.6) & $3(9.1)$ & 15 (16.9) & & \\
\hline Total & & $33(100)$ & $89(100)$ & & \\
\hline \multicolumn{6}{|l|}{ GWG } \\
\hline GWG $<8.9$ & $68(55.3)$ & $25(35.8)$ & $43(63.2)$ & 3.42 (CI 1.29-9.28) & $0.02^{*}$ \\
\hline GWG9-14.9 & $45(36.6)$ & $7(15.6)$ & $38(84.4)$ & & \\
\hline GWG $>15$ & $10(8.1)$ & $1(10)$ & $9(90)$ & & \\
\hline \multicolumn{6}{|l|}{$\mathrm{Hb}$} \\
\hline $\mathrm{Hb}<10.9$ & $56(45.5)$ & 19 (33.9) & 37 (66.1) & 1.9 (CI $0.86-4.3)$ & 0.15 \\
\hline $\mathrm{Hb}>11$ & $67(54.5)$ & 14 (19.1) & 53 (79.9) & & \\
\hline \multicolumn{6}{|c|}{$\begin{array}{l}\text { P value by Chi Square test. } \\
\text { Computed as } 2 \text { X2 for variables of BMI ( }<18.4 \text { and more), GWG ( }<8.9 \text { and more) and } \mathrm{Hb}(<10.9 \text { and more). } \\
\text { CI - Confidence Interval. } \\
\text { "p-significant at }<0.05 \text {. }\end{array}$} \\
\hline
\end{tabular}

Table 2 - Maternal characteristics in birth weight (g) groups (Mean \pm SD).

\begin{tabular}{|c|c|c|c|c|c|c|c|}
\hline \multirow[t]{2}{*}{ Variables } & \multirow[t]{2}{*}{$\begin{array}{l}\text { Birth } \\
\text { weight }\end{array}$} & \multirow[t]{2}{*}{ Mean } & \multirow[t]{2}{*}{$\mathrm{SD}$} & \multicolumn{2}{|c|}{$\begin{array}{l}\text { 95\% Confidence } \\
\text { interval for mean }\end{array}$} & \multirow[t]{2}{*}{ Significance by LSD } & \multirow[t]{2}{*}{$P$ value } \\
\hline & & & & $\begin{array}{l}\text { Lower } \\
\text { bound }\end{array}$ & $\begin{array}{l}\text { Upper } \\
\text { bound }\end{array}$ & & \\
\hline \multirow[t]{4}{*}{ Age } & $<2.49 \mathrm{~kg}$ & 24.51 & 3.73 & 23.19 & 25.83 & The three groups are not significant to each other & 0.536 \\
\hline & $2.5-3.0 \mathrm{~kg}$ & 25.29 & 3.77 & 24.19 & 26.38 & & \\
\hline & $>3.0 \mathrm{~kg}$ & 25.47 & 3.92 & 24.18 & 26.76 & & \\
\hline & Total & 25.13 & 3.79 & 24.44 & 25.82 & & \\
\hline \multirow[t]{4}{*}{ SEST } & $<2.49 \mathrm{~kg}$ & 17.54 & 4.99 & 15.77 & 19.31 & The three groups are not significant to each other & 0.358 \\
\hline & $2.5-3.0 \mathrm{~kg}$ & 18.56 & 5.08 & 17.08 & 20.03 & & \\
\hline & $>3.0 \mathrm{~kg}$ & 19.31 & 5.43 & 17.53 & 21.10 & & \\
\hline & Total & 18.52 & 5.17 & 17.58 & 19.46 & & \\
\hline \multirow[t]{4}{*}{ GWG } & $<2.49 \mathrm{~kg}$ & 8.30 & 2.53 & 7.40 & 9.20 & Group 1 is significantly different from Group 3 & $0.000^{*}$ \\
\hline & $2.5-3.0 \mathrm{~kg}$ & 9.39 & 3.26 & 8.44 & 10.34 & Group 2 is significantly different from Group 3 & $0.01^{*}$ \\
\hline & $>3.0 \mathrm{~kg}$ & 11.02 & 2.60 & 10.17 & 11.88 & Group 1 and Group 2 are not significant & 0.095 \\
\hline & Total & 9.61 & 3.04 & 9.06 & 10.16 & & \\
\hline \multirow[t]{4}{*}{$\mathrm{Hb}$} & $<2.49 \mathrm{~kg}$ & 10.43 & 1.19 & 10.01 & 10.86 & Group 1 is significantly different from Group 3 & $0.01^{*}$ \\
\hline & $2.5-3.0 \mathrm{~kg}$ & 10.82 & 1.15 & 10.49 & 11.16 & $\begin{array}{l}\text { Rest of the groups are not significantly different } \\
\text { from each other }\end{array}$ & \\
\hline & $>3.0 \mathrm{~kg}$ & 11.22 & 1.62 & 10.69 & 11.75 & & \\
\hline & Total & 10.84 & 1.35 & 10.60 & 11.09 & & $0.049^{*}$ \\
\hline \multirow{4}{*}{$\begin{array}{l}\text { BMI at 1st } \\
\text { trimester }\end{array}$} & $<2.49 \mathrm{~kg}$ & 21.17 & 3.79 & 19.82 & 22.51 & The three groups are not significant to each other & \\
\hline & $2.5-3.0 \mathrm{~kg}$ & 22.13 & 3.77 & 21.03 & 23.22 & & \\
\hline & $>3.0 \mathrm{~kg}$ & 22.34 & 3.08 & 21.32 & 23.34 & & 0.35 \\
\hline & Total & 21.92 & 3.57 & & & & \\
\hline
\end{tabular}

P value calculated by ANOVA, Test of Homogeneity - not significant, ${ }^{*} p<0.05$ - significant. Significance between the groups tested by LSD. SEST - Socio economic Status Total Score (Kuppuswamy), GWG - Gestational Weight gain, BMI - Body Mass Index, Hb - Hemoglobin. 
birth weight outcome (Table 1), which might be a cause for concern. This could be due to not following proper nutritional guideline during the period of the pregnancy. Similar results were found in an Indian study by Kader $\mathrm{M}^{7}$ when comparing thin mothers and mothers with normal BMI. Multiparity was also associated with low birth weight (Table 1) as established in other studies. ${ }^{8}$

The weight gain in the LBW group was significantly different from the normal weight group corroborates the lack of proper nutrition in this group and is similar to most of the other studies. ${ }^{3,7-9}$ Anemia was also present significantly in the LBW group. Other than deficiency of iron rich food in the diet, hookworm infestation may also be implicated in this urban population who were mostly from the near by slum, an important catchment area of the population.

Energy, fat and micronutrient deficiencies in women before conception and during pregnancy have been implicated in causing low birth weight in infants ${ }^{2,3,8,9}$ and there is an extra requirement of good quality proteins, iron and calcium. ${ }^{3}$ In our study, there were more non vegetarians $(64.22 \%$ vs $35.77 \%$ ) but good quality of dietary intake in the form of milk, green leafy vegetables, eggs, vegetable oil and fleshy foods were found to be far from satisfactory as also found in the Pune Maternal Nutrition Study. ${ }^{8}$ However, chance of having normal birth weight babies were found to be more in non vegetarians. A higher proportion (73.62\%) women had milk regularly and had a normal birth weight baby.

One limitation of the study was that the dietary intake was not quantified. Quantification of dietary intake, usually done by $24 \mathrm{~h}$ recall, might be erroneous and misinterpreted specially in pregnant women and in a small population. Lack of data on gestational age, which is considered to be a risk factor by many studies, was another limitation.

\section{Conclusion}

A high prevalence of less than recommended maternal weight gain along with a coexistence of low quality dietary intake associated with high prevalence of LBW require further introspection and research. The issue of proper nutritional counseling during antenatal check ups, is required for all mothers during pregnancy and also for all women of child bearing age, irrespective of BMI status. Balanced protein, energy and micronutrient supplementation during pregnancy had been a matter of debate for ages, but have been frequently used by doctors, mostly in the private sector but not as a Government policy. Increased investment in health infrastructure may be able to prevent around half the childhood morbidity and mortality, but preventing the other half has to be a result of synergisitic effects of improved food intake, increased food and micronutrient supplementation and nutritional education of the pregnant woman and her family. ${ }^{10}$ A deeper understanding of the linkages, relationships and behavior among the components of the health system may be further required for a favorable long term outcome in improving the neonatal birth weight.

Scaling up right nutrition for mothers will thus offer a profound system wide effect and a unique opportunity in our progress towards both the Millennium Development Goals 4 (Reduce child mortality) \& 5 (Improve maternal health).

\section{Conflicts of interest}

All authors have none to declare.

\section{Acknowledgment}

The study was carried out as a departmental project under the Dept of Community Medicine and the author acknowledges contribution of Dept of Obstetrics and Gynaecology, Armed Forces Medical College, Pune.

\section{R E F E R E N C E S}

1. Muthayya S. Maternal nutrition \& low birth weight - what is really important? Indian J Med Res. 2009;130:600-608.

2. Ministry of Health and Family Welfare: National Family Health Survey 3, India. Available from: http://mohfw.nic.in/nfhs3/CD htm. Accessed 06.07.14.

3. Black RE, Allen LA, Bhutta ZA, et al, for the Maternal and Child Undernutrition Study Group. Maternal and child undernutrition: global and regional exposures and health consequences. Lancet. 2013;382:427-451.

4. Committee on Obstetrics Practice. Weight gain during pregnancy. Am Coll Obstetrics Gynaecol. 2013;548. Available from: http://www.acog.org/Resources-And-Publications/ Committee-Opinions/Committee-on-Obstetric-Practice/ Weight-Gain-During-Pregnancy. Accessed 14.02.15.

5. National Institute of Nutrition. Recommended Dietary Allowances for Indians. 2010:590.

6. Kumar A, Chaudhary K, Prasad S. Maternal indicators and obstetric outcome in the north Indian population: a hospitalbased study. J Postgrad Med. 2010;56:192-195.

7. Kader M, Nirmala KP. Socio-economic and nutritional determinants of low birth weight in India. North Am J Med Sci. Jul 2014;6:302-308.

8. Rao S, Yagnik CS, Kanade A, et al. Intake of micronutrientrich foods in rural Indian mothers is associated with the size of their babies at birth: Pune Maternal Nutitional Study. J Nutr. 2001;131:1217-1224.

9. Velusamy SK, Jeyaseelan Lakshmanan, Tunny S, Annie R, Jiji M, Ruby J. New birth weight reference standards ustomized to birth order and sex of babies from South India. BioMed Central Pregnancy Childbirth. 2013;13:38.

10. Shyama K, Julian S, David B, Sadia C, Daniele C, Laura F. Success factors for reducing maternal and child mortality. Bull World Health Organ. 2014;92:533-544. 